\title{
BMJ Open Effectiveness of case-based learning in Chinese dental education: a systematic review and meta-analysis
}

\author{
Haitao Dong, Chunlan Guo (D) , Lian Zhou, Jizhi Zhao, Xiaomin Wu, Xinyuan Zhang, \\ Xin Zhang
}

To cite: Dong H, Guo C, Zhou L, et al. Effectiveness of casebased learning in Chinese dental education: a systematic review and meta-analysis. BMJ Open 2022;12:e048497. doi:10.1136/ bmjopen-2020-048497

- Prepublication history for this paper is available online. To view these files, please visit the journal online (http://dx.doi. org/10.1136/bmjopen-2020048497).

Received 30 December 2020 Accepted 31 January 2022

Check for updates

(c) Author(s) (or their employer(s)) 2022. Re-use permitted under CC BY-NC. No commercial re-use. See rights and permissions. Published by BMJ.

Department of Stomatology, Peking Union Medical College Hospital, Chinese Academy of Medical Sciences and Peking Union Medical College, Beijing, China

Correspondence to Dr Chunlan Guo; guocl001@126.com

\section{ABSTRACT}

Objective The application of case-based learning (CBL) pedagogy has been emerging as an improved and more practical learning method across the Chinese dental education system. This article provides a critical overview of CBL pedagogy and further assesses the effectiveness of this teaching model in Chinese dental education.

Design A systematic review and meta-analysis.

Methods Studies published up to December 2019

were searched in the following electronic databases: China National Knowledge Infrastructure, China Science Periodical Database, Chinese Biomedical documental database, Wanfang data, PubMed, EMBASE and Cochrane Central Register of Control Trials. All randomised controlled trials (RCTs) that compared the effectiveness of the CBL teaching model and the traditional lecture-based learning (LBL) model in all dental disciplines were included. The assessment of methodological quality was based on the guidelines described in the Cochrane Handbook for Systematic Reviews, and the meta-analysis was performed using the software RevMan V.5.3

Results A total of 30 RCTs were finally included, with a total sample size of 2356 dental students. The CBL pedagogy significantly increased knowledge scores (standardised mean difference $(\mathrm{SMD})=1.58,95 \% \mathrm{Cl}: 0.95$ to $2.20, \mathrm{p}<0.0001)$, skill scores $(\mathrm{SMD}=1.22,95 \% \mathrm{Cl}$ : 0.34 to $2.11, p<0.0001$ ), comprehensive ability scores (SMD $=1.91,95 \% \mathrm{Cl}: 1.74$ to $4.07, \mathrm{p}<0.0001)$ and teaching satisfaction (risk ratio $=1.38 ; 95 \% \mathrm{Cl}: 1.15$ to $1.65 ; \mathrm{p}=0.01$ ) compared with the LBL teaching model among the dental students. Additionally, a subgroup analysis showed significant differences in the effects of CBL on knowledge scores, skill scores and comprehensive ability scores when comparing theoretical and practical courses.

Conclusions The meta-analysis and systematic review of the eligible literature showed that the CBL pedagogy in Chinese dental education is an effective way to increase knowledge scores, skill scores, comprehensive ability scores and teaching satisfaction. Successful adaptation of this teaching model could solve the scarcity of highly skilled and professional dentists in dental schools and hospitals across China.

\section{INTRODUCTION}

Dental education typically exploits the conventional methods of didactic, disciplinebased curricula to increase students'

\section{Strengths and limitations of this study}

This is the first systematic review and meta-analysis of case-based learning (CBL) practice in Chinese dental education.

- It gives us some beneficial proposal to implementing the CBL pedagogy in future.

- The included studies were research in the field of medical education, so it is impossible for the researchers to implement allocation concealment and blinding.

- Methodology qualities of the included studies represent a major limitation of this review.

- Measurement bias exists in this review, for there is no standard criterion for evaluating the effectiveness of the CBL pedagogy in the included studies.

competency with those skills and professional values in a subject-centred matter. ${ }^{1}$ The traditional didactic lecture-based curriculum uses an instructor-centred classroom setting in which students are passive listeners rather than active learners. Hence, the effectiveness of such teaching methods in equipping the graduates with a broad range of essential dental competencies, such as critical thinking and treating the patients comprehensively, is questionable. Notably, surveys in faculty members have reported that in most cases, graduate students could not efficiently implement their didactic preclinical knowledge into the actual clinical application when it comes to patient care. ${ }^{2}$ As a result, long-established case-based learning (CBL) pedagogy, which originated from Harvard Medical School in the 1920s, has emerged as an effective teaching model innovation in health professional education, including dental education.

CBL methods generally focus on using wide ranges of medical and clinical cases to teach students about actual patient care situations. In these curricula, the teachers mainly guide the students to implement their acquired 
knowledge foundation in making decisions on problems that they may encounter in practice. So, the studentteacher relationship goes on like that, the students take on the learning responsibilities by analysing the given case and designing effective treatment strategy, while the teacher's role is a prompter and guide to help students justify their analyses. The implementation process of CBL can be summarised as follows: establishment of the case $\rightarrow$ case grouping and analysis $\rightarrow$ brainstorming $\rightarrow$ identifying instruction goals $\rightarrow$ new findings $\rightarrow$ exchanging results between groups $\rightarrow$ reaching learning consensus and integrating the consensus into clinical practice. ${ }^{3}$ CBL is increasingly becoming a popular teaching model applied in dental education in Europe, the USA, Canada, Australia and New Zealand since the 1990s, and some studies in these regions suggested that CBL is more effective in fostering deep learning, and efficient retention of analytical and diagnostic knowledge among students. ${ }^{4}$ CBL may also facilitate competency development in students in a manner that parallels their future professional career goals. ${ }^{5}$

In the early 21 st century, the Chinese dental education system realised the crucial systemic obstructions in transforming a dental graduate into a skilled and professional dentist who was in great demand. To overcome this roadblock, some of the well-known key Chinese dental schools, including Shanghai Second Medical University, School of Stomatology at the Fourth Military Medical University and School of Stomatology at Wuhan University, took critical steps forward to greatly reform the contemporary dental education models. These models included the most effective teaching concepts and were already being applied in diverse educational strategies, like CBL pedagogy. For the past 20 years, the CBL curriculum has been gradually adopted by several more dental schools across China, subsequently presenting its increasing success rates. In general, CBL curricula cover nearly all dental disciplines, including oral medicine, periodontology, prosthodontics, paediatric dentistry, orthodontics, preclinical training, etc. This kind of broad application of CBL methodology in the Chinese dental education system has been vividly reflected in the increasing number of publications of medical studies focusing on the CBL teaching model in China. Thus, this meta-analysis aimed to systematically review the effectiveness of CBL pedagogy performed in the Chinese dental education system. To evaluate the overall effectiveness, we performed subgroup analyses of the studies conducted in China to identify the benefits of the application of different types of courses in terms of knowledge scores, skill scores and comprehensive ability scores, as well as teaching satisfaction.

\section{METHODS}

\section{Study design}

The study methods used for this meta-analysis and systematic review were based on the recommended Preferred
Reporting Items for Systematic Reviews and Meta-Analyses checklist guidelines. ${ }^{6}$

\section{Search strategy}

The published studies and trials were searched in the following Chinese electronic databases: China National Knowledge Infrastructure, China Science Periodical Database, Chinese Biomedical documental database and Wanfang data. Moreover, the following English-language electronic databases-PubMed, EMBASE and Cochrane Central Register of Controlled Trials-were searched. Next, the abstracts of the additional eligible studies posted in the international and national conference proceedings were also screened. The end date for all the electronic database searches was restricted to December 2019. The specific set of MeSH terms or keywords used to search the above databases was like ("case-based learning" OR "CBL") AND ("dental* OR dental* education OR dental* students") AND ("China"). There was no search restriction on language. Furthermore, the reference lists of these selected articles were reviewed for additional related reports.

\section{Selection criteria}

There were four inclusion criteria: (1) the studies were randomised controlled trials (RCTs); (2) the participants for the studies were undergraduate and graduate students of dental institutions in China; (3) the interventions included the CBL pedagogy in the experimental group covering all dental disciplines and traditional teaching methods (lecture-based learning, LBL) in the control group; neither the experiment nor the control group should be exposed to supplementary teaching methods that could have an impact on the results; and (4) the outcomes presented as data or descriptions of each RCT included at least one of the following scores: knowledge score, skill score, comprehensive ability score, pass rate and teaching satisfaction.

Any study which did not meet the above criteria was excluded. The titles and abstracts of all retrieved articles were independently reviewed by two reviewers (HD and CG) to identify potential studies. The full texts of the eligible studies were then obtained and assessed independently by the two reviewers. Any discrepancies were resolved by discussion with a third reviewer (LZ) until a consensus was met.

\section{Data extraction}

Data were collected and extracted by two independent reviewers (HD and CG) using a predefined data form, which included studies regarding basic characteristics, such as the first authors, year of publication, involved dental disciplines, characteristics and numbers of the participants, intervention methods and outcome measures. Any conflict on the eligibility of the extracted information by these two reviewers was resolved by discussion among themselves or intervention of the third reviewer. 


\section{Outcomes}

The primary outcomes in this meta-analysis were knowledge scores, skill scores, comprehensive ability scores in the CBL group and the LBL group. The secondary outcomes were pass rate and teaching satisfaction. In the included studies, the teaching satisfaction was usually evaluated by a Likert scale. From 5 to 1 , the decrease of the scores means the decline of satisfaction. When the scores were 5 4, teaching satisfaction was defined as significant. When the scores were 3 2, teaching satisfaction was defined as general. When the scores were 1 , teaching satisfaction was defined as poor. Subgroup analyses were conducted to assess the benefits of applying CBL versus $\mathrm{LBL}$ to theoretical and practical courses in the above outcomes.

\section{Quality assessment}

The methodological qualities of the included studies were assessed as adequate, inadequate or uncertain independently by the two reviewers (HD and CG) using guidelines described in the Cochrane Collaboration for Systematic Reviews of Interventions. ${ }^{7}$ Any disagreement was resolved through discussion. The quality assessment was based on six general sources of bias described as random sequence generation, allocation concealment, blinding, incomplete outcome data, selective reporting and other sources of bias contained in this specific study as the meaningful evaluation index. The overall methodological quality of each study was included as 'low risk of bias', 'high risk of bias' and 'uncertain risk of bias'. Information addressed by these items was retrieved from the published studies, and authors were contacted in case any additional information was needed.

\section{Statistical analysis}

Statistical analysis to test the heterogeneity of data and the meta-analysis was carried out using the Review Manager (RevMan) software (V.5.3, the Cochrane Collaboration, UK). For continuous outcomes, such as knowledge scores, skill scores, comprehensive ability scores, the standardised mean difference for effect size based on sample size and $95 \%$ CIs were calculated from the same scale. For dichotomous outcomes, such as pass rate and teaching satisfaction, the risk ratio (RR) and 95\% CI were calculated. If the data could not be pooled, descriptive statistics were used only. Publication bias was tested independently using funnel plots of knowledge scores, skill scores, comprehensive ability scores and teaching satisfaction; if the funnel plot was symmetric, there was a low potential for publication bias, and vice-versa.

\section{Role of the funding source}

This work was supported by Peking Union Medical College Postgraduate Education Reform Program (grant number: 10023201900102). The funding body provided financial support for the preparation of the article in the collection, analysis and interpretation of data; in the

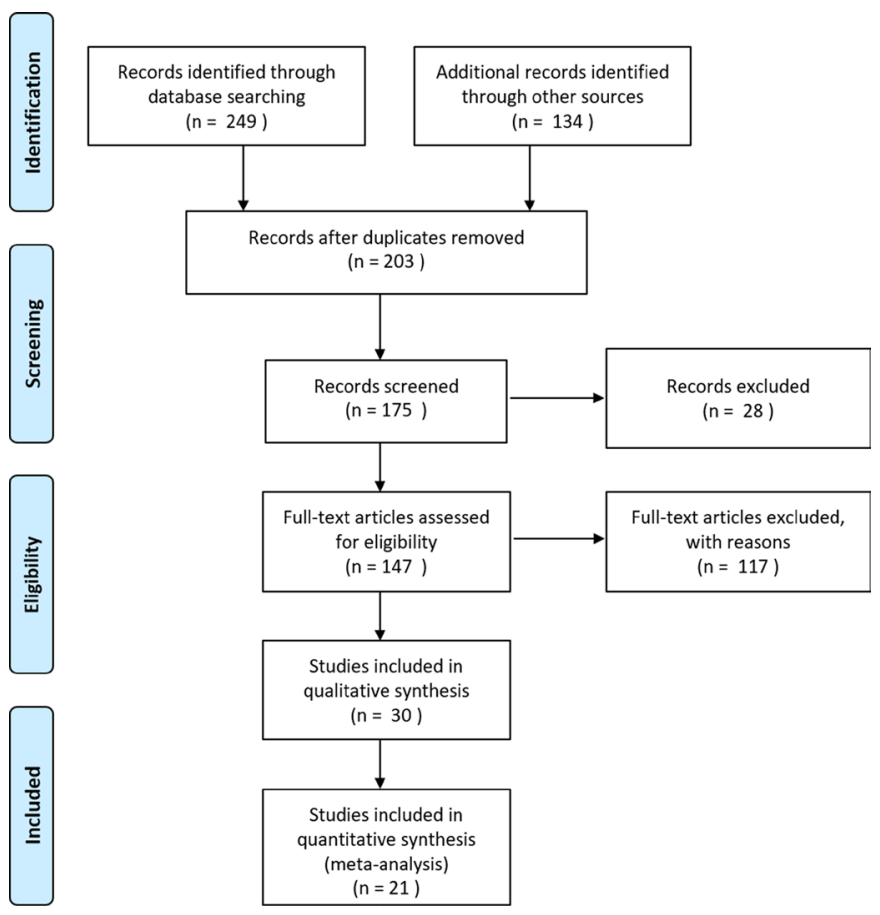

Figure 1 Flow diagram of study selection (Preferred Reporting Items for Systematic Reviews and Meta-Analyses).

writing of the report; and in the decision to submit the paper for publication.

\section{Patient and public involvement}

Since this is a systematic review and meta-analysis, patients and the public were not involved in the design or planning of the study.

\section{RESULTS}

\section{Search results}

The details on study inclusion and exclusion are summarised in the flow diagram (figure 1). The literature search in the databases yielded a total of 383 studies in the initial search, out of which 167 records were removed as duplicates, resulting in 216 records. After applying the selection criteria, 175 records were selected. Based on their titles and abstracts, a further 28 studies were excluded because some were experience summaries, and others were questionnaire surveys without theoretical measurement of the scores. The full texts of the remaining 147 studies were reviewed, and the additional 117 records were also excluded since they were trials without controls or CBL combined with supplementary teaching methods. Thus, a total of 30 studies, $^{8-37}$ involving pooled 2356 dental graduate students, met the inclusion criteria, which were subsequently selected for this meta-analysis. All of the included studies were published between 2008 and 2019. These studies included 1198 students in the CBL teaching group and 1158 students in the LBL group. In these cohorts, most of the participating students were seniors. The sample size in the included trials ranged from 20 to 200 participants. Among these 30 studies, 1 


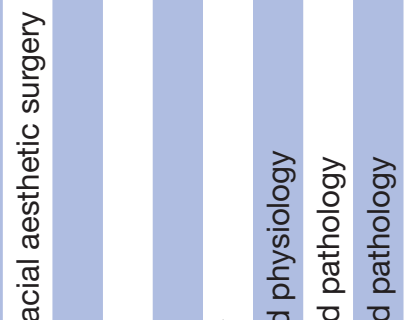

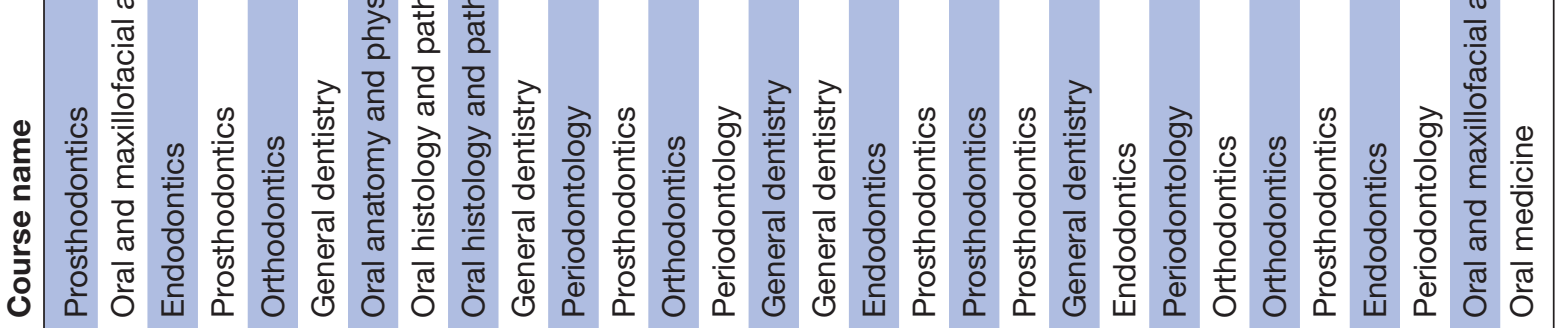

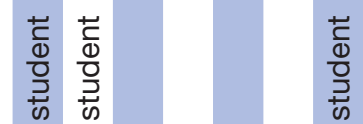

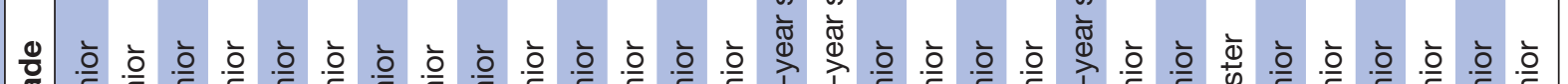

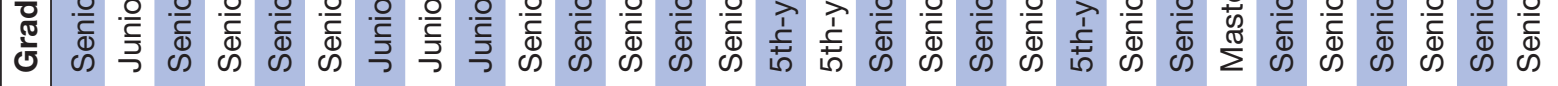

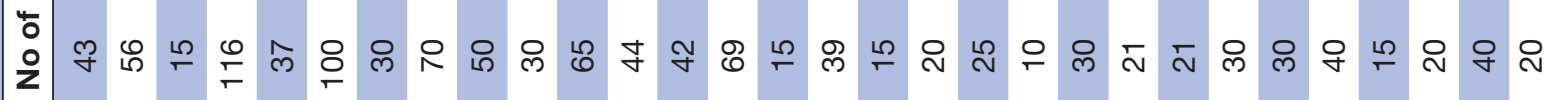

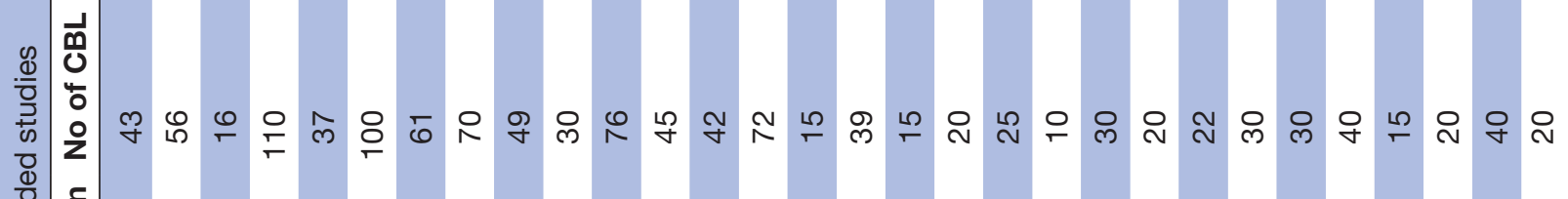

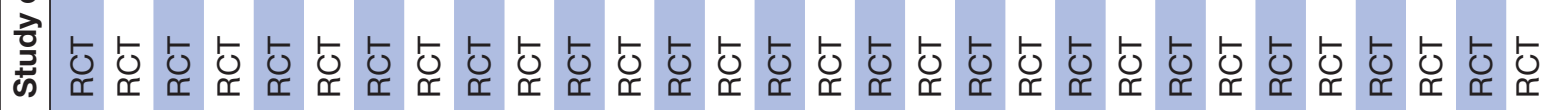

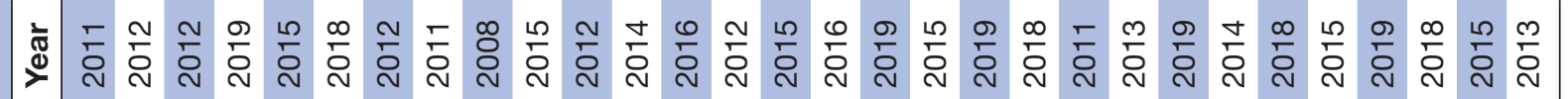
0 


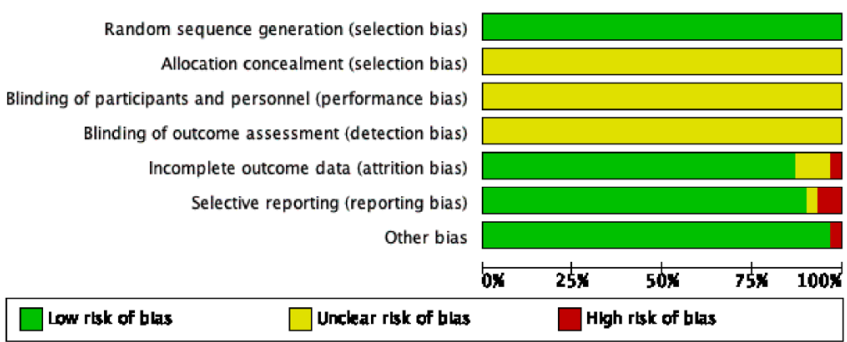

Figure 2 Risk of bias graph: review authors' judgements about each risk of bias item presented as percentages across all included studies.

study $^{37}$ was published in English, and the others were published in Chinese. The types of dental disciplines included in the studies were prosthodontics, $8111926-2833$ endodontics, ${ }^{10253034}$ periodontology, ${ }^{18} 213135$ orthodontics, ${ }^{12} 2032$ oral medicine, ${ }^{37}$ general dentistry, ${ }^{13} 172227$ oral and maxillofacial aesthetic surgery, ${ }^{96}$ oral anatomy and physiology, ${ }^{14}$ and oral histology and pathology. ${ }^{15} 16$ There were $18 \mathrm{RCTs}^{8} 9$ 12-20 26-28 32333537 on theoretical courses, and $12 \mathrm{RCTs}^{10}{ }^{11}$ 21-25 29-31 3436 on practical courses. The basic characteristics of the 30 included studies are presented in table 1 .

The quality of the 30 studies was evaluated using the Cochrane Collaboration Handbook for Systematic Reviews. There were eight studies ${ }^{13} 20262831343537$ reporting the detailed information of the randomisation sequence generation, all of which were generated using the randomised number chart. However, none of the studies reported the allocation concealment methods and blinding. The summary of the methodological quality of each study is shown in figure 2. The meta-analysis independently used funnel plots of knowledge scores, skill scores, comprehensive ability scores and teaching satisfaction to assess publication bias (figure 3A-D). The shape of the funnel plot was nearly symmetrical, indicating negligible evidence of significant publication bias.

\section{Measurements of knowledge scores}

Twenty-six of the included studies reported relevant data regarding knowledge scores. Among these, four studies ${ }^{11} 161728$ reported dichotomous data, such as pass rate, excellence rate and improvement rate. Because of the diversity-mediated heterogeneity of data, the outcomes were not pooled. The remaining 22 studies $^{8-22} 24252728$ 30-32 3637 reported the continuous data, such as mean scores and SD, which were pooled in this meta-analysis (904 and 857 students in the CBL and LBL groups, respectively). The meta-analysis of the knowledge scores found that the CBL pedagogy significantly increased the knowledge scores by a mean of 1.58 compared with that of LBL pedagogy (95\% CI: 0.95 to 2.20; $\mathrm{p}<0.00001)$. The random-effects model was used for the meta-analysis because of the higher heterogeneity of the data $\left(\mathrm{p}<0.00001, \mathrm{I}^{2}=97 \%\right)$ (figure 4).

\section{Measurements of skill scores}

Eight studies ${ }^{10} 21232931$ 34-36 documented relevant data regarding skill scores (252 and 249 students in the CBL and LBL groups, respectively). The meta-analysis of the skill scores found that the CBL pedagogy significantly
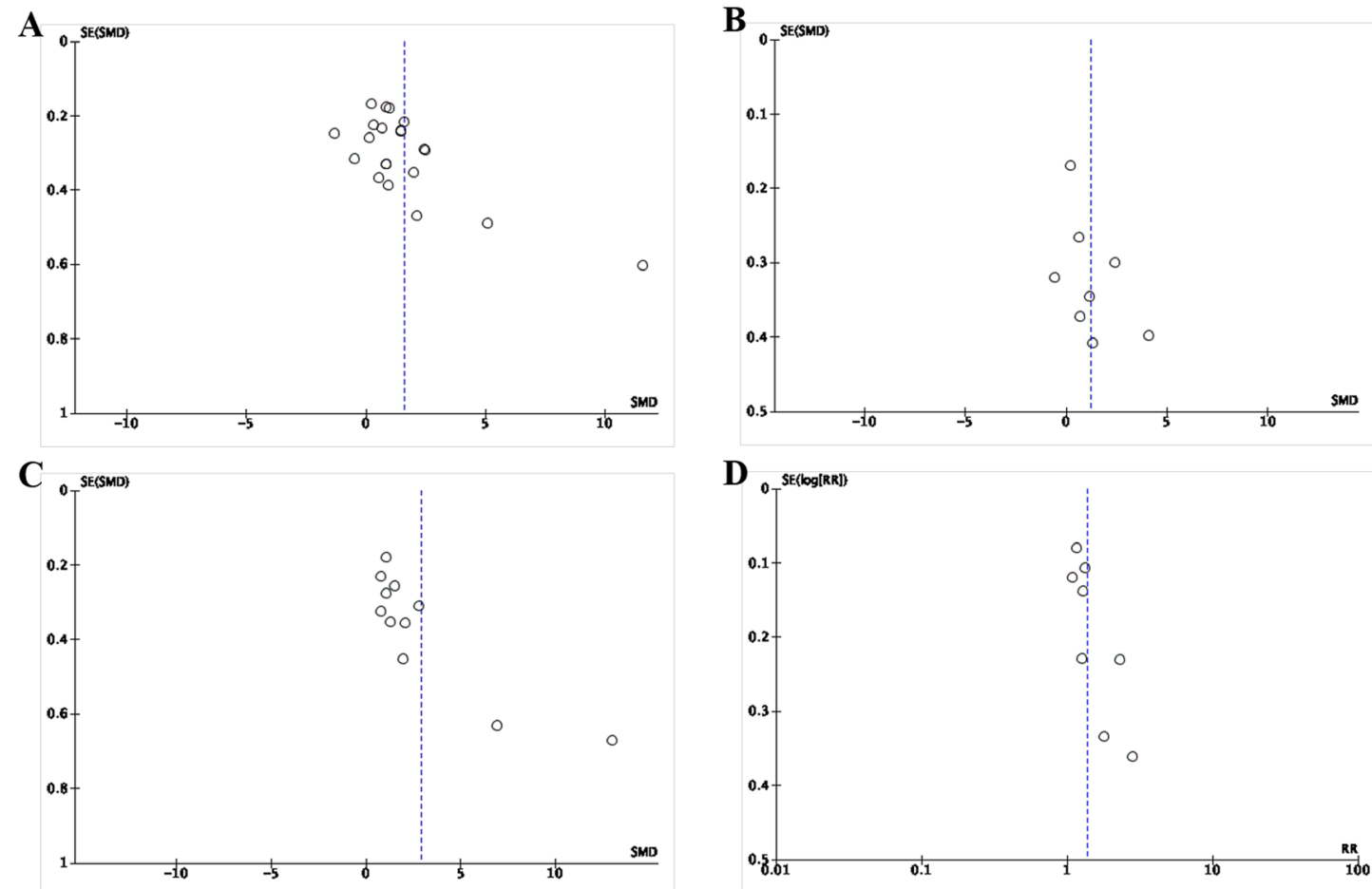

Figure 3 Funnel plots for publication bias. (A) Publication bias of knowledge scores; (B) publication bias of skill scores; (C) publication bias of comprehensive ability scores; (D) publication bias of satisfactory teaching effect. RR, risk ratio; SMD, standardised mean difference. 


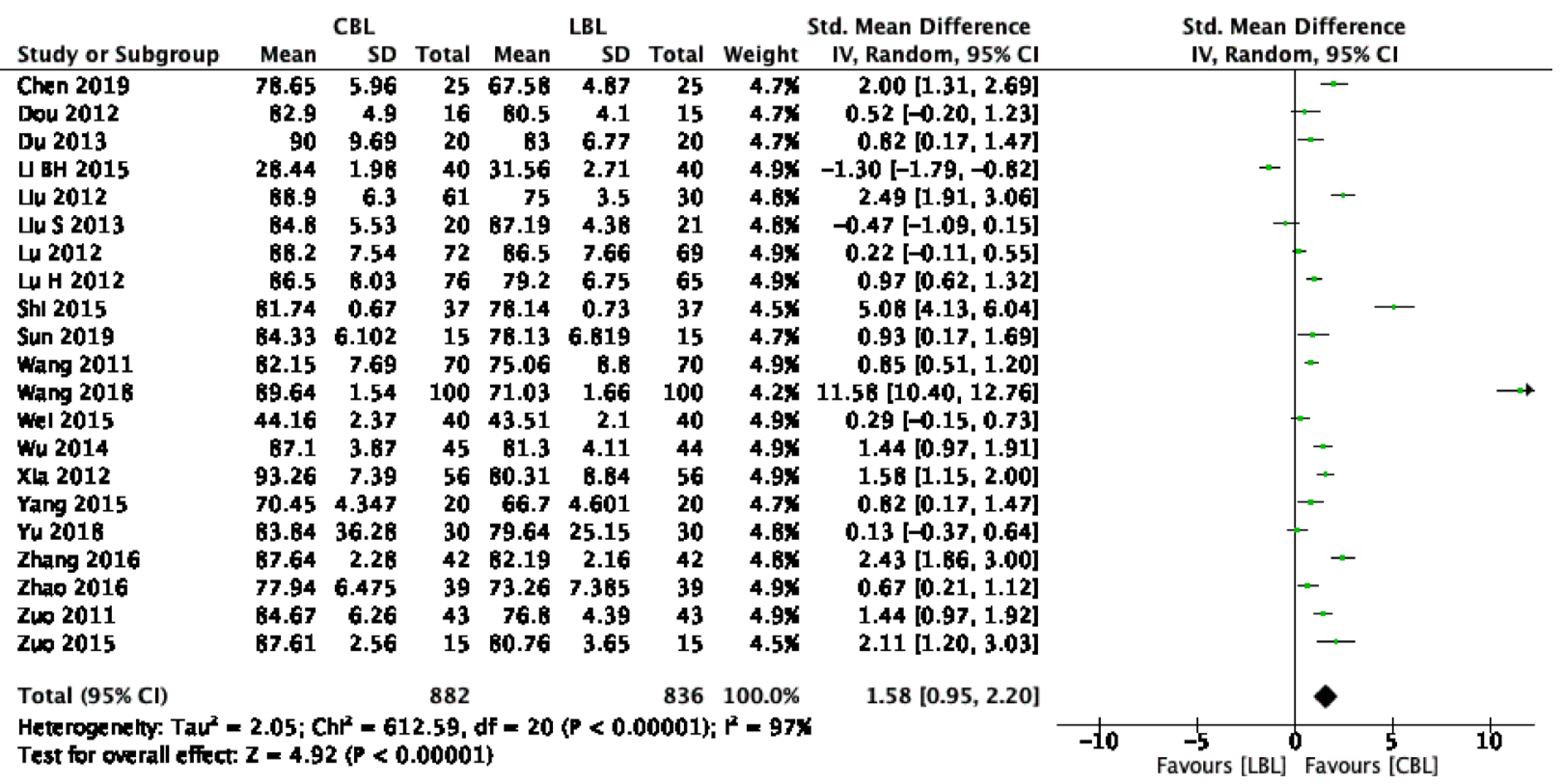

increased skill scores by a mean of 1.22 compared with that of LBL teaching model (95\% CI: 0.34 to 2.11; $\mathrm{p}<0.0001)$. The random-effects model was used for the meta-analysis because of the higher heterogeneity of the data $\left(\mathrm{p}<0.00001, \mathrm{I}^{2}=95 \%\right)$ (figure 5$)$.

\section{Measurements of comprehensive ability scores}

Eleven studies ${ }^{12} 13$ 20-22 24-26 29-32 produced relevant data regarding comprehensive ability scores (441 and 439 students in the CBL and LBL groups, respectively). The meta-analysis of the comprehensive ability scores found that the CBL teaching model significantly increased comprehensive ability scores by a mean of 2.91 compared with that of the LBL teaching model (95\% CI: 1.74 to 4.07; $\mathrm{p}<0.0001)$. The random-effects model was used for the meta-analysis because of the higher heterogeneity of the data $\left(\mathrm{p}<0.0001, \mathrm{I}^{2}=98 \%\right)$ (figure 6$)$.

\section{Measurements of teaching satisfaction}

Teaching satisfaction was divided into three dimensions: satisfactory teaching effect, general teaching effect and poor teaching effect. A total of eight studies $^{10} 1315-17283036$ reported relevant data regarding satisfactory teaching effects (340 and 340 students in the CBL and LBL groups, respectively). The meta-analysis of satisfactory teaching effect on the CBL teaching model found higher satisfactory rates compared with that of the LBL teaching model (RR: $1.38 ; 95 \%$ CI: 1.15 to $1.65 ; \mathrm{p}=0.01$ ). The random-effects model was used for the meta-analysis because of the higher heterogeneity of the data $\left(p=0.01, I^{2}=68 \%\right)$ (figure 7 ). There were no complete data to pool the general teaching effect and poor teaching effect between the CBL and LBL groups.

\section{Subgroup analysis}

Subgroup analysis was performed to examine the differences between practical and theoretical courses when CBL was applied instead of LBL methods. Table 2 shows the results of the subgroup analysis. The outcome revealed that there were significant differences in the effects of CBL on knowledge scores, skill scores and comprehensive ability scores when comparing theoretical and practical courses. In addition, a subgroup analysis of the level of training showed that the CBL teaching model also

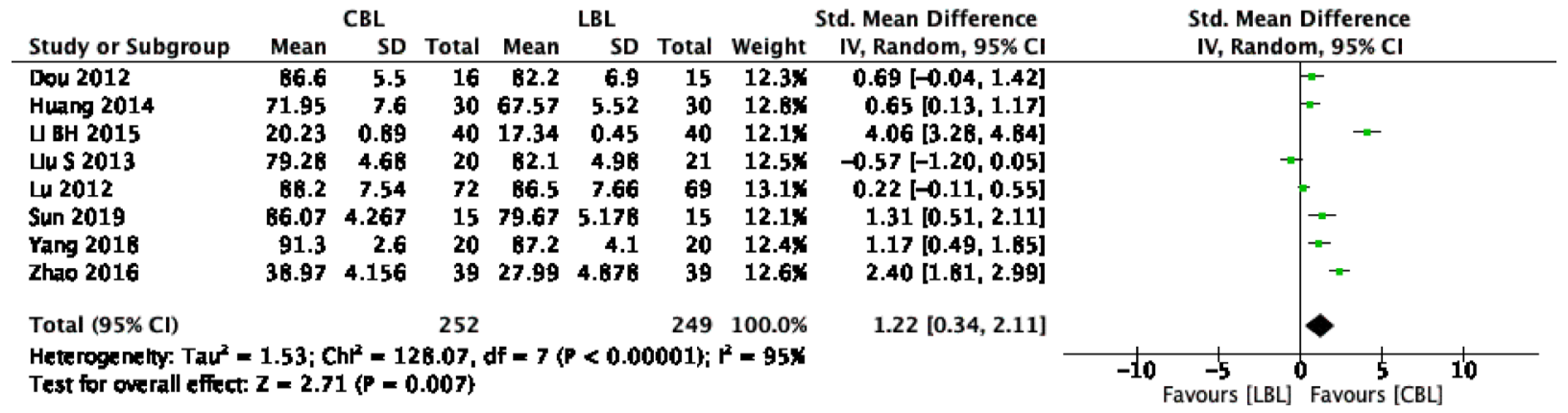

Figure 5 Forest plot of skill scores for CBL compared with LBL. CBL, case-based learning; LBL, lecture-based learning. 


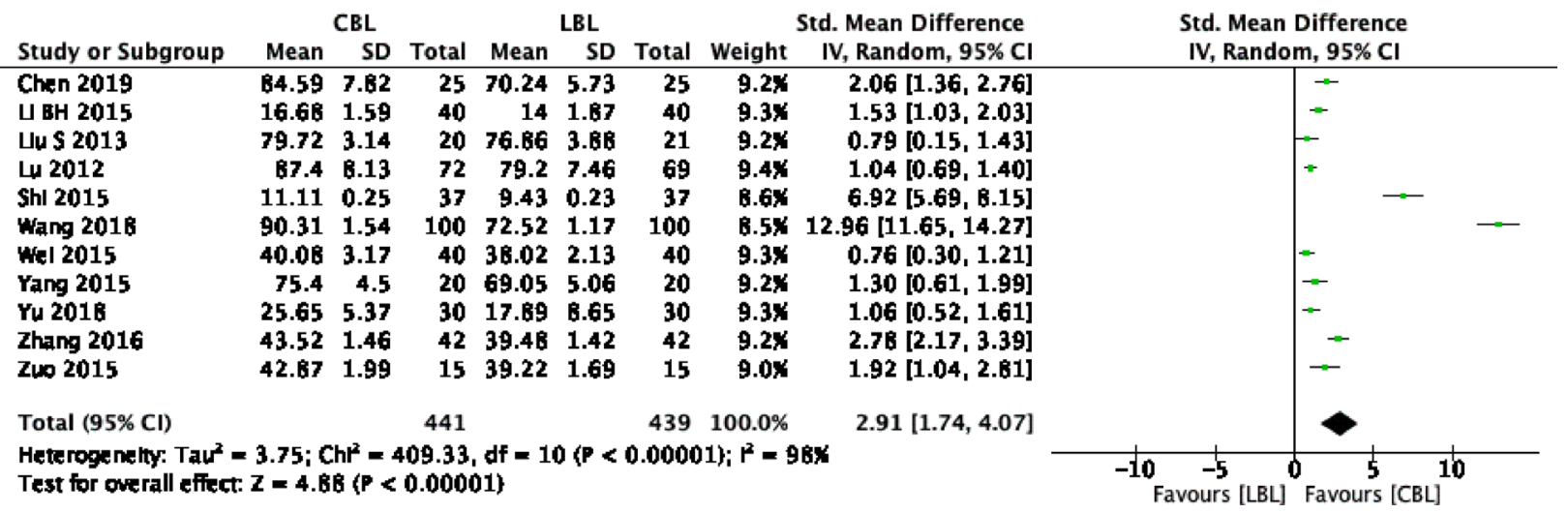

Figure 6 Forest plot of comprehensive ability scores for CBL compared with LBL. CBL, case-based learning; LBL, lecturebased learning.

significantly improved the knowledge scores of senior and 5th-year students (table 3).

\section{DISCUSSION}

Since the beginning of the 21st century, worldwide medical education, including dentistry, has increasingly emphasised the development of realistic clinical competencies as well as educational milestones of the graduates. The definition of competency in dentistry has been made by the working party of the Competencies for Dental Licensure in Canada as, "competency is most often used to describe the skills, understanding and professional values of an individual ready to begin independent dental or allied oral health care practice'. ${ }^{38}$ At the professional level, the Commission on Dental Accreditation proposed that dental students' competencies should include critical thinking and acquisition of evidence-based information in clinical reasoning and problem-solving. ${ }^{39} \mathrm{CBL}$ pedagogy, as an important element of competency-based education, typically focuses on the discussion of a patient case, and the fundamental concepts required for understanding the case are presented via lectures and/or readings before conducting case discussion. In these courses, teachers become a critical guide in assisting students in enriching their dynamic thought processes rather than passively acquiring information. CBL has been emerging as an outstanding start to transit students from more traditional and theoretical 'textbook'-oriented methodologies to practical scenarios. This unique academic concept enables students to think holistically, starting from presenting the medical history and diagnostics to the social aspects of the patient's quality of life during and after the course of treatments. This teaching strategy has shown to increase the students' interest to learn deeply about the realistic clinical practice and also prepares the students with a mindset to work in an interdisciplinary group, the advantages of which can then be seen to amplify further replenishing the deficiency of highly skilled dentists.

Unlike developed countries, CBL has not been a routine pedagogy in Chinese dental education. There have been certain inhibitory factors against the broadspectrum implementation of CBL in China. First, the traditional teacher-centred model has been dominating the dental education system in China for decades, which has almost established predefined educational experiences for both the students and teachers. Hence, it is evident that there will be a long-term adaption period to adjust the CBL teaching pattern and assessment system for both the teachers and students. Second, the levels and standards of dental education vary dramatically among different schools in China. The scarcity of high-quality

\begin{tabular}{|c|c|c|c|c|c|c|}
\hline Study or Subgroup & $\begin{array}{c}\text { CBL } \\
\text { Events }\end{array}$ & Total & $\begin{aligned} & \text { LBL } \\
& \text { Events }\end{aligned}$ & Total & Weight & $\begin{array}{c}\text { Risk Ratio } \\
\text { M-H, Random, } 95 \% \mathrm{Cl}\end{array}$ \\
\hline Chen 2019 & 23 & 25 & 18 & 25 & $15.4 \%$ & $1.2 \mathrm{~B}[0.98,1.67]$ \\
\hline Dou 2012 & 15 & 16 & 13 & 15 & $16.8 \mathrm{x}$ & $1.05[0.85,1.37]$ \\
\hline บ BH 2015 & 32 & 40 & 14 & 40 & $9.5 \%$ & $2.29[1.46,3.5 \mathrm{~B}]$ \\
\hline Lang $200 B$ & 22 & 49 & B & 50 & $5.1 \mathrm{x}$ & $2.81[1.3 \mathrm{~B}, 5.69]$ \\
\hline ᄂ40 2018 & 9 & 10 & 5 & 10 & $5.7 \%$ & $1.80[0.94,3.46]$ \\
\hline Wang 2011 & 58 & 70 & 44 & 70 & $17.9 \times$ & $1.32[1.07,1.62]$ \\
\hline Wang 2015 & 19 & 30 & 15 & 30 & $9.5 \mathrm{x}$ & $1.27[0.81,1.99]$ \\
\hline Wang 2018 & 82 & 100 & 70 & 100 & $20.0 \%$ & $1.17[1.00,1.37]$ \\
\hline Total $(95 \% \mathrm{Cl})$ & & 340 & & 340 & $100.0 \%$ & $1.38[1.15,1.65]$ \\
\hline $\begin{array}{l}\text { Total events } \\
\text { Heterogeneity: Ta } \\
\text { Test for overall eff }\end{array}$ & $\begin{array}{l}260 \\
04 ; C h \\
=3.48\end{array}$ & & $\begin{array}{r}187 \\
6, \mathrm{df}\end{array}$ & 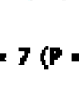 & 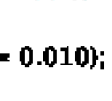 & \\
\hline
\end{tabular}

Figure 7 Forest plot of teaching satisfaction for CBL compared with LBL. CBL, case-based learning; LBL, lecture-based learning. 
Table 2 Results of subgroup analyses in the current meta-analysis

\begin{tabular}{|c|c|c|c|c|c|c|c|c|}
\hline \multirow[b]{2}{*}{ Items } & \multicolumn{3}{|c|}{ No of participants } & \multirow[b]{2}{*}{$P$ value } & \multicolumn{3}{|l|}{ Incidence } & \multirow[b]{2}{*}{ Model } \\
\hline & Studies & CBL & LBL & & SMD/RR & $95 \% \mathrm{Cl}$ & Heterogeneity $\left(\mathrm{I}^{2}\right)$ & \\
\hline \multicolumn{9}{|l|}{ Knowledge scores* } \\
\hline Practical courses & 7 & 226 & 185 & $<0.0001$ & 1.1 & 0.34 to 1.86 & $91 \%$ & Random \\
\hline \multicolumn{9}{|l|}{ Skill scores* } \\
\hline Practical courses & 6 & 212 & 209 & 0.02 & 0.83 & 0.15 to 1.51 & $90 \%$ & Random \\
\hline \multicolumn{9}{|c|}{ Comprehensive ability scores* } \\
\hline Theoretical courses & 7 & 309 & 309 & $<0.0001$ & 3.81 & 1.88 to 5.74 & $98 \%$ & Random \\
\hline Practical courses & 4 & 132 & 130 & 0.01 & 1.39 & 0.82 to 1.97 & $72 \%$ & Random \\
\hline \multicolumn{9}{|l|}{ Teaching satisfaction† } \\
\hline
\end{tabular}

*Values presented as mean difference and $95 \% \mathrm{Cl}$.

†Values presented as RR and $95 \% \mathrm{Cl}$.

$\mathrm{CBL}$, case-based learning; LBL, lecture-based learning; No, number; NS, non-significant; RR, risk ratio; SMD, standardised mean difference.

and energetic teaching teams is a significant inhibitory factor against the successful implementation of the CBL pedagogy. Third, the CBL curricula should be based on the sound fundamental knowledge background of the students. Notably, dental students in China usually have to complete the multidisciplinary dental courses including restorative dentistry, preventive dentistry, periodontology, prosthodontics, paediatric dentistry and oral medicine within 1-1.5 years of course duration, which is totally different from the dental education patterns in developed countries, such as the USA. ${ }^{40}$ The time limitations make dental schools employ less time-consuming teaching models to fit well within the scheduled period. Hence, a great deal of educational reformation, rearrangement, and successful integration between academia and professional hospitals are urgently required to vividly improve the Chinese dental education system.

The key findings of this meta-analysis suggested that the CBL pedagogy could significantly increase knowledge scores, skill scores, comprehensive ability scores and teaching satisfaction compared with that of the traditional LBL teaching model. Subgroup analyses also consistently demonstrated that the knowledge scores and comprehensive ability scores between practical and theoretical courses were significantly different, and satisfactory teaching effects in practical courses were significant. According to the questionnaire-based surveys of the students, CBL aroused their learning enthusiasm, trained them to improve their critical thinking ability, brought their interests toward working as a team, and enabled them to integrate and manage learning resources effectively and actively, and promoted self-study capacity.

As we know, this is the first systematic review and meta-analysis of CBL practice in Chinese dental education. Compared with other reviews on teaching methods reform in Chinese dental education previously, such as meta-analysis on problem-based learning practice in Chinese dental education published by Huang et $a l,{ }^{40}$ the present study had two strengths. First, a subgroup analysis

Table 3 Subgroup analyses of the level of training in the current meta-analysis

\begin{tabular}{|c|c|c|c|c|c|c|c|c|}
\hline \multirow[b]{2}{*}{ Items } & \multicolumn{3}{|c|}{ No of participants } & \multicolumn{5}{|c|}{ Incidence } \\
\hline & Studies & CBL & LBL & P value & SMD/MD & $95 \% \mathrm{Cl}$ & Heterogeneity $\left(1^{2}\right)$ & Model \\
\hline \multicolumn{9}{|l|}{ Knowledge scores* } \\
\hline Senior & 22 & 686 & 671 & 0.001 & 1.53 & 0.75 to 2.31 & $97 \%$ & Random \\
\hline 5th-year student & 3 & 82 & 82 & 0.007 & 1.05 & 0.29 to 1.81 & $81 \%$ & Random \\
\hline
\end{tabular}

*Values presented as MD and 95\% Cl.

CBL, case-based learning; LBL, lecture-based learning; MD, mean difference; No, number; SMD, standardised mean difference. 
was performed comparing the course type between the theoretical courses and the practical courses. Second, this study independently used funnel plots to assess publication bias. The plots were generally symmetrical and showed a lower publication bias.

However, there were also several limitations in the present study. The methodology qualities of the included RCTs were not significantly high. None of them reported the allocation concealment and blinding sources. There was significant heterogeneity of the data among the 22 pooled studies with respect to knowledge scores, the 8 pooled studies with respect to skill scores and the 11 pooled studies with respect to comprehensive ability scores. The following factors might have led to these diversities: (1) the pooled studies focused on different dental disciplines; (2) the heterogeneity of the reported results, including knowledge scores and skill scores, was significantly high; (3) there were no guidelines to implicate CBL for different disciplines; (4) there were no standard criteria for the evaluation of the teaching effect of CBL pedagogy. Therefore, more scientifically designed RCTs in this field will be needed in the future to address these issues.

To better apply and study the CBL teaching model in Chinese dental education background, first, teachers should design an effective teaching programme based on teaching experiences that could facilitate and improve the students' ability to think critically and treat patients comprehensively on the basis of their sound fundamental knowledge of the dental sciences; second, teachers should develop or select realistic intriguing cases which link theoretical knowledge to practical aspects through inquiry-based learning methods, and simulate scenarios by simultaneously taking into account the patient's medical, dental, psychological, socioeconomic and cultural conditions; third, the teaching method of CBL is a three-dimensional cooperative relationship, which includes the dominant relationships between teachers and students, among students, and between virtual and realistic patientdoctor scenario. In the CBL teaching model, students are placed at the centre of the educational teaching network. Students should be engaged in multimodal activities such as information-gathering, higher-order analytical thinking, synthesis and evaluation of the case-specific treatment strategy. In this way, the CBL curriculum would stimulate students' active learning capacity, and help them demonstrate the equivalent or superior preparation skills for key competencies compared with the requirements in their day-to-day professional life. Future studies should aim to assess the impact of the CBL on students' outcomes and to develop a better understanding of their learning experiences within the CBL framework in comparison with those they have during didactic courses.

In summary, this meta-analysis revealed that the CBL pedagogy could be an effective method for increasing the knowledge scores, skill scores, comprehensive ability scores, as well as toward improving teaching satisfaction among the dental graduates in China. CBL appears to be superior to traditional lecture-based teaching methods. Thus, the use of the CBL teaching model may be optimal for improving dental education in China. However, the heterogeneity of the data from the included studies and the relatively low qualities of statistically validated measures should be taken into account in future practice, suggesting an urgent necessity for high-quality studies to efficiently assess the effectiveness of CBL pedagogy in the Chinese dental education system.

Contributors HD, XinyuanZ and XinZ carried out the entire procedure including the literature search and data extraction, performed the statistical analysis, and drafted and revised the manuscript. JZ and XW contributed to the revision of the manuscript. CG and LZ conceived of the study, coordinated and participated in the entire process of drafting and revising the manuscript.

Funding This work was supported by Peking Union Medical College Postgraduate Education Reform Program (grant number: 10023201900102).

Competing interests None declared.

Patient and public involvement Patients and/or the public were not involved in the design, or conduct, or reporting, or dissemination plans of this research.

Patient consent for publication Not required.

Ethics approval Prior ethical approval was not necessary because it is a review of previously published articles and does not involve any processing of individual patient data.

Provenance and peer review Not commissioned; externally peer reviewed.

Data availability statement Data are available in a public, open access repository.

Open access This is an open access article distributed in accordance with the Creative Commons Attribution Non Commercial (CC BY-NC 4.0) license, which permits others to distribute, remix, adapt, build upon this work non-commercially, and license their derivative works on different terms, provided the original work is properly cited, appropriate credit is given, any changes made indicated, and the use is non-commercial. See: http://creativecommons.org/licenses/by-nc/4.0/.

ORCID iD

Chunlan Guo http://orcid.org/0000-0001-7030-151X

\section{REFERENCES}

1 Yip HK, Smales RJ. Review of competency-based education in dentistry. Br Dent J 2000;189:324-6.

2 Behar-Horenstein LS, Catalanotto FA, Nascimento MM. Anticipated and actual implementation of case-based learning by dental faculty members during and after training. J Dent Educ 2015;79:1049-60.

3 Zhang SY, Zheng JW, Yang C, et al. Case-Based learning in clinical courses in a Chinese College of stomatology. J Dent Educ 2012;76:1389-92.

4 Ilgüy M, llgüy D, Fișekçioğlu $\mathrm{E}$, et al. Comparison of case-based and lecture-based learning in dental education using the solo taxonomy. J Dent Educ 2014;78:1521-7.

5 Keeve PL, Gerhards U, Arnold WA, et al. Job requirements compared to dental school education: impact of a case-based learning curriculum. GMS Z Med Ausbild 2012;29:Doc54.

6 Higgins JPT, Altman DG, Gøtzsche PC, et al. The Cochrane collaboration's tool for assessing risk of bias in randomised trials. BMJ 2011;343:d5928.

7 Higgins JPT, Thompson SG. Quantifying heterogeneity in a metaanalysis. Stat Med 2002;21:1539-58.

8 Zuo EJ, SH H, XJ L. Data from: application of case teaching method combined with traditional teaching method in theoretic teaching of prosthodontics (in Chinese). Chinese Higher Medical Education 2011;04:101-2.

9 Xia P, Sui CD. Data from: application of case-based teaching in oral medical teaching (in Chinese). Chinese Journal of Aesthetic Medicine 2012;21:1403-4. 
10 Dou L, Qin J, Yang DQ. Data from: application of Cbl teaching method in clinical practice of oral medicine. Basic Medical Education 2012;14:530-2.

11 Jiang LY. Data from: application of $\mathrm{Cbl}$ teaching method in prosthetic (in Chinese). Information Weekly 2019;33:422.

12 Shi YL, Pan WW, Zhang J. Data from: application of Cbl teaching method in orthodontics (in Chinese). Health Vocational Education 2015;33:54-5.

13 Wang Y. Data from: application of $\mathrm{Cbl}$ teaching method for oral health care students education (in Chinese). General Journal Of Stomatology 2018;32:128-31.

14 Liu BH, Zhang CQ, Zhang YT. Data from: application of Cbl teaching method in oral and anatomy and physiology. Journal of Qiqihar University of Medicine 2012;33:938-9.

15 Wang X, SH W, Liu LY. Data from: case-based teaching method applied in teaching of oral histology and pathology (in Chinese). China Medical Education Technology 2011;25:73-6.

16 Liang CY, Huang ZY, Yang WJ. Data from: application of Cbl teaching method in oral and anatomy and physiology for adult students (in Chinese). Data from: Anatomy Research 2008;30:389-91.

17 Wang XM, Cao XF, Xie XH. Data from: using case-based teaching in stomatology (in Chinese). Chinese Higher Medical Education 2015;4:42-3.

18 Lu H, Tian Y, Wang QT. Data from: application of Cbl teaching method in periodontology (in Chinese). North-west Medical Education 2012;20:407-9.

19 Wu J, Tian M, GF W. Data from: application of web based course on $\mathrm{Cbl}$ method in the Prosthodontic teaching (in Chinese). China Modern Medicine 2014;22:797-9.

20 Zhang CY. Data from: analysis of application of evidence -based medical idea combined with case teaching method in the orthodontics teaching (in Chinese). China Health Industry 2016;13:125-7.

21 Lu H, Tian Y, Wang QT. Data from: application of case-based learning combined the evidence-based medicine in the intern teaching of periodontology (in Chinese). Chin J Conserv Dent 2012;2:118-20.

22 Zuo EJ, Niu WD, GW M. Data from: application of evidence-based medicine thinking combined with case-based learning in clinical practice teaching of general dentistry (in Chinese). Chin J Conserv Dent 2015;25:758-61.

23 Zhao L, Yan L, Sun HL. Data from: the exploration of application of $\mathrm{Cbl}$ and traditional teaching methodology in clinical teaching of stomatology (in Chinese). Heilongjiang Medicine and Pharmacy 2016;39:55-7.

24 Wang L, Huang WM, Yang DQ. Data from: application of Cbl teaching method in endodontics (in Chinese). Continuing Medical Education 2019;33:50-1.
25 Yang YF, Liu HX, Zhao QJ. Data from: application of Cbl teaching model in the teaching of removable partial denture (in Chinese). Chin $J$ Dent Mater Dev 2015;24:50-2.

26 Chen DD. Data from: application value of $\mathrm{Cbl}$ teaching method in the teaching of removable partial denture (in Chinese). China Modern Medicine 2019;26:194-6.

27 Liao M. Data from: application of $\mathrm{Cbl}$ teaching model in dental education (in Chinese). General Journal Of Stomatology 2018;31:155-60.

28 Tao L, Tang Y, Zhu M-yi, et al. [Application of case-based learning in clinical practice of dental students]. Shanghai Kou Qiang Yi Xue 2011;20:209-12.

29 Liu S-bo, Peng B, Song Y-ling, et al. [Application of case-based learning in clinical internship teaching of conservative dentistry and endodontics]. Shanghai Kou Qiang Yi Xue 2013;22:711-4.

30 CJ H, Feng YH, Shi MY. Data from: Application of case-based learning method in undergraduates' clinical probation in periodontology (in Chinese). Shanghai Medicine and Pharmacy 2018;39:3-5.

31 Huang QQ, Zhang Y, Deng F. Data from: application of case-based learning in orthodontics clinical practice (in Chinese). Heilongjiang Medicine and Pharmacy 2014;37:14-15.

32 XL Y, Dai HT, XJ L. Data from: application of Cbl teaching method in orthodontic teaching (in Chinese). Science and Education Journal 2018;18:134-9

33 Wei JY, Zhou XW, Wang LB. Data from: application of Cbl teaching model in prosthetics (in Chinese). China Continuing Medical Education 2015;10:20-1.

34 Sun Y, Yin BD, HX L. Data from: using Cbl in the lab sessions of endodontics (in Chinese). Chinese Higher Medical Education 2019;2:67-8.

35 Yang K, QM H, Gao L. Data from: using $\mathrm{Cbl}$ in the lab sessions of periodontology (in Chinese). Continuing Medical Education 2018;32:80-2.

$36 \mathrm{BH}$ L, Yang ZC, XH Y. Data from: the application of PBL and Cbl in esthetic oral maxillofacial surgery (in Chinese). Education teaching forum 2015;16:82-3.

37 Du G-F, Li C-Z, Shang S-H, et al. Practising case-based learning in oral medicine for dental students in China. Eur J Dent Educ 2013;17:225-8.

38 Boyd MA, Gerrow JD, Chambers DW, et al. Competencies for dental licensure in Canada. J Dent Educ 1996;60:842-6.

39 Nadershahi NA, Bender DJ, Beck L, et al. An overview of case-based and problem-based learning methodologies for dental education. $J$ Dent Educ 2013;77:1300-5.

40 Huang B, Zheng L, Li C, et al. Effectiveness of problem-based learning in Chinese dental education: a meta-analysis. J Dent Educ 2013;77:377-83. 